Unhappily, in spite of the wide usefulness the book will undoubtedly have, the book is flawed by personal animus against a few scientists, and by occasional lapses into slangy diction. Cells do not "quit" making interferon, and sentences like "Studies on the mechanisms controlling the transcription and translation of interferons will likely soon enable better artificial regulation of these mechanisms, to provide sufficient interferon messenger RNA to allow its retrocopy into prokaryotic cells from which clones interferon can become truly abundant"' make one gasp.

D. C. Burke is Professor of Biological Sciences at the University of Warwick, Coventry, UK. He has worked on interferon since April, 1957, starting to collaborate with the late Dr Alick Isaacs and Professor Jean Lindenmann a month or two after the initial discovery.

\section{Elements of cloning}

\section{Marie A. DiBerardino}

Cloning: A Biologist Reports. By R.G. McKinnell. Pp. 130. (University of Minnesota Press: Minneapolis, 1979.) $\$ 8.95$.

PROFESSOR MCKINNELL terminates his book with the following three sentences in the epilogue: "Cloning is one of many experimental procedures that provide information that may help in solving problems such as cancer and ageing. That is the why of cloning. And to assist people in understanding that "why - i.e., the rationale of cloning - I have written this book". The author has accomplished his objective. He is a research biologist who has carried out nuclear transplantation studies (one form of cloning) directed towards understanding normal cell differentiation, cancer, immunobiology and ageing. Few scientists possess both the authoritative background and literary talent to communicate accurately the relevance of bench-work research to its future potential for solving biomedical problems. McKinnell, however, manages to convey the significance of this basic research to the non-scientist.

McKinnell begins his book by correcting erroneous and inflamnatory statements about cloning and points out that the cloning of plants has been in practice for over 4000 years and has served to enrich man with beauty and food. This process is achieved by means of asexual reproduction resulting in a genetic replicate of the parent, whereas sexual reproduction involves the combination of genes from two parents and thus produces an individual containing a diversity of genetic traits.

The author then embarks on a description of classical animal studies carried out during the late nineteenth and early twentieth centuries that laid the ground-work for the amphibian cloning experiments. During this period there occurred a fusion of the disciplines of genetics, embryology and cytology; and the central problem that occupied these early scientists was the theory of nuclear equivalence. They sought to determine whether the diverse specialised cells of an organism retain the same set of genes as the nucleus of the fertilised egg. The earliest scientists recognised the stability of the differentiated state, that is, liver remains liver even if a person lives beyond ninety years, as pointed out by McKinnell. To explain this phenomenon, a theory of genetic differences among the progeny of the zygote nuleus was proposed by Weismann to account for the origin of cell diversity and stability. However, this proposal was refuted at least for nuclei from the earliest stages of development by the primitive cloning experiments of Loeb in the sea urchin and later of Spemann in the salamander. Finally, in 1952 "a fantastical experiment" termed and proposed by Spemann, was accomplished by Briggs and King. They sought to extend the primitive cloning experiments and transplanted a living nucleus from a cell from a frog blastula embryo, a day old, into a frog egg whose own nucleus had been removed surgically. The blastula embryo contained thousands of cells all derived from a zygote nucleus, but these blastula nuclei were still capable of promoting eggs to develop into normal larvae and eventually in later studies into normal frogs, demonstrating that the donor nuclei contained a set of genes equivalent to the zygote nucleus. This prototype experiment has been repeated many times in various amphibian species throughout the world, and it is now well established that many nuclei from early embryonic stages are totipotent. The theory of nuclear equivalence is still the central problem of developmental genetics today. The cloning studies have been most extensively carried out in two amphibian forms - the leopard frog, Rana pipiens, and the South African frog, Xenopus laevis. Cloning experiments have shown that during the course of embryogenesis, transplanted nuclei become progressively restricted in their ability to promote normal development of the eggs; and so far no nucleus of an adult cell has programmed an egg to develop normally. Despite this, a most extraordinary result does occur when nuclei from adult cells are cloned. A small percentage of eggs develops through embryogenesis to early larval stages and contain all the cell types and tissues of a larva, indicating that an extensive gene complement is still present and functional. Similarly, frog nuclei from adult kidney tumours when transplanted to eggs also lead to the formation of larvae. This subject, an area in which the author has made important research contributions, is discussed at some length. He points out that the formerly held pessimistic view of the irreversibility of cancer has been alleviated by these and other experiments. Thus, although important strides have been made in studying problems of normal cell differentiation and cancer, much more needs to be done in the future. McKinnell proposes: "If more were known about cancer-cell genetic material and about regulating its differentiated state, there would be the rational hope that a cancer chemotherapeutic agent could be devised that would regulate differentiation of these malignant cells"'.

Although amphibian cloning has been the most extensively studied among multicellular organisms, there has also been some work done on insects and fish. However, attempts at mammalian cloning have so far not been successful. But McKinnell points out that many of the techniques are available and the expectation that the remaining ones will be solved is encouraging. Cloning of farm animals may have agricultural advantages - for example, one could select for outstanding milk production, quality of wool, disease resistance, and so on; and this approach would be extremely faster than selective breeding for genetic traits.

Finally, McKinnell reviews some of the concepts of human cloning theorised by science-fiction writers, philosophers, theologians and lawyers. He addresses himself as a biologist and expert cloner to the social, ethical and biological problems inherent in their suggestions. Among his various refutations he emphasises that cloning may result in genetic replicates but not carbon copies, a widely misunderstood point. He also points out that species are successful due to the diversity of genes available through sexual reproduction, and so cloning is not a sound reproductive method.

McKinnell has performed an important service for both scientists and nonscientists in his well balanced and critical review of cloning, and at an appropriate time when both groups need an accurate account of the applications of nuclear transplantation studies to the biomedical sciences, in order to evaluate the erroneous and exaggerated notions of cloning that have been perpetrated upon the public. This book will be especially invaluable to non-specialists. A series of superb illustrations, together with the clarity and simplicity of prose, will permit the nonspecialist to understand the basic elements of cloning and its biomedical implications.

Marie A. DiBerardino is Professor of Anatom at the Medical College of Pennsylvania, Philadelphia. Dr DiBerardino began her nuclear transplantation studies with the originators of cloning (Briggs and King) during the 1950s. 